\title{
Optimisation of an in-process lineal dielectric sensor for liquid moulding of carbon fibre
}

\section{composites}

\author{
T.S. Mesogitis ${ }^{1}$, G. M. Maistros ${ }^{2}$, M. Asareh ${ }^{3}$, C. Lira', A.A. Skordos ${ }^{3 *}$
}

${ }^{1}$ National Composites Centre (NCC), Feynman Way Central, Bristol \& Bath Science Park, Emersons Green, Bristol, BS16

7FS

${ }^{2}$ ADVISE-DETA Ltd. 34 Castle Rd., Bedford MK40 3PJ

${ }^{3}$ School of Aerospace, Transport and Manufacturing

Cranfield University, Cranfield, Bedfordshire MK43 0AL

*Corresponding author (a.a.skordos@cranfield.ac.uk)

\begin{abstract}
A dielectric sensor appropriate for process monitoring of carbon fibre composites manufacturing has been optimised and implemented in Resin Transfer Moulding (RTM). The sensor comprises a pair of twisted insulated copper wires and can be adapted to monitor both flow and cure. To simulate the dielectric response of the sensor, an electric field model was developed. The model was coupled with a multi-objective optimisation genetic algorithm to optimise the sensor design. The optimisation showed that increasing wire radius and decreasing coating thickness increases sensor sensitivity. Different sensor designs were implemented and used in a series of RTM trials to validate the technology in industrial conditions. The sensor operated successfully at pressures up to 7 bar and temperatures up to $180^{\circ} \mathrm{C}$. A low diameter sensor using copper wire coated with polyimide showed the best response monitoring flow with an accuracy of $95 \%$, whilst also following the cure and identifying vitrification.
\end{abstract}

Keywords: A. Carbon fibres; C. Computational modelling; D. Process monitoring; E. Resin transfer moulding (RTM) 


\section{Introduction}

The need to track manufacturing parameters such as flow front position and degree of cure during the manufacturing process of composite materials has led to the continuous development of process monitoring techniques in the last decades. The filling process in the case of liquid moulding processes is monitored using lineal and spot sensors. Lineal sensors are based on dielectrics [1, 2], time domain reflectometry [3], Direct Current measurements (DC) [4, 5] and fibre optics [6] techniques. Spot sensors such as fibre optics [7, 8], pressure transducers [9-11] and thermocouples can provide valuable information around resin arrival. Cure sensors track the evolution of a physical quantity related directly or indirectly to the cure state of the material. There is a series of different methods to monitor cure such as infrared spectroscopy [12, 13], near- infrared spectroscopy [14-16], fibre optic techniques [9, 17-19, 20] and dielectric cure monitoring [21-28]. Dielectrics have in general high sensitivity given the significant contrast in dielectric properties between filled and unfilled regions, robustness associated with the strength of electrode materials involved compared to composites processing pressures and low cost connected with the wide availability of sensing elements and measuring equipment. A novel lineal dielectric sensor comprising two twisted insulated copper wires appropriate for process monitoring in the presence of carbon fibre was developed recently [29]. Up to this development monitoring techniques were mostly appropriate for process monitoring in the presence of electrically nonconductive materials such as glass fibres, whereas use with carbon required adaptations to eliminate electrical interference. This increases system complexity and makes the technology difficult to use. The developed sensor [29] was successfully utilised in Liquid Composite Moulding (LCM) set-ups demonstrating its capability to monitor the manufacturing process accurately.

This study aims at the optimisation of this new monitoring technology in terms of sensitivity of the dielectric response through optimising the sensor geometry and coating material and in terms of robustness in industrial RTM conditions. To this end, the following contributions were made in this study:

- An electric field model was developed and implemented using the Finite Element Analysis (FEA) code FlexPDE [30]. The model is able to predict the distribution of the electric field as well as the real and imaginary admittance response at different frequencies.

- A multi-objective optimisation Genetic Algorithm (GA) [31] was adapted and coupled with the electric field model to maximise both the real and imaginary dielectric response sensitivity of the sensor. Four design parameters were optimised: electrode wire radius, coating thickness, coating real permittivity and coating dielectric loss. 
- $\quad$ The optimised sensors were tested successfully in industrial RTM runs at pressures reaching 7 bar in a press clamping tool.

\section{Sensor principle of operation}

The dielectric sensor comprises two twisted solid copper wires coated with an insulating material. The insulator prevents contact of the copper wires with electrically conductive fibres [29]. Upon application of voltage an electric field is formed between the wires. The electric field goes through the insulator penetrating the gaps between the twisted wires. The air gaps between the wires and the sensor effective length is increased by the twisting resulting in stronger signal. The conductive fibres can interfere with the fringing field; however, they only screen it partially. The sensor design can be adapted to address both flow and cure monitoring applications. The resin flow front position can be monitored using a lineal twisted sensor as shown in Figure 1. The significant contrast in dielectric properties between liquid resin and air results in considerable sensor response sensitivity to its wetted length [29].

In the case of cure monitoring, the local state of the material is estimated based on the electrical properties sensitivity on the progression of cure [29]. The concept of the cure sensor is based on a woven configuration of the twisted wires as shown in Figure 2. The signal strength is dictated by the total length of the sensor. The woven configuration allows a high wire length to sensor area ratio, thus increasing the sensitivity of the sensor. The use of coating overcomes the difficulties caused by electrical shorting in contact with carbon fibre reinforcement [29]. This circumvents the use of veils or glass cloths on the sensor to ensure electrical insulation from the conductive carbon fibre. As the available air pockets between the wires increase due to twisting, the signal is strengthened allowing the monitoring of the cure state of the resin. This configuration can result in a relatively small size sensor allowing implementation in complex geometries where other monitoring technologies such as pressure sensors require tool modifications [29].

The lineal sensor response is based on the analysis described in [1]. The wetted length can be calculated as follows:

$$
L_{w}=\frac{Y-Y_{o}}{Y_{f}-Y_{o}} L
$$

where $Y$ is the instantaneous admittance measured by the sensor, $L$ the total sensor length, $Y_{o}$ the admittance of the dry sensor and $Y_{f}$ the admittance of the fully wetted sensor. As shown in Eq. (1) the flow front position presents a linear relationship with the lineal sensor response. The total sensor length $L$ is a function of the wire 
diameter, twists per unit length and the actual length of the twisted wires. Increasing all three parameters increases $L$. The strength of the signal is proportional to the actual length of the wires and $L$. In the case of cure monitoring the response is translated to information expressing the resin reaction state. Three phenomena occur when a thermoset is under AC electrical excitation: dipolar relaxation, charge migration and electrode polarisation. The electrical behaviour of a lossy dielectric material such as a curing epoxy is dominated by migrating charges and a small contribution by dipolar relaxation. The response of migrating charges is utilised in cure monitoring applications, through an impedance representation and determination of the imaginary impedance maximum in the frequency spectrum [32,33]. Vitrification can also be monitored based on impedance measurements, as dipolar relaxation causes a shoulder in the evolution of imaginary impedance at fixed frequency [34].

In the case of flexible tooling liquid composite moulding the sensor can be fed into the mould through the sealant tape. In the case of closed moulded RTM the sensor can be fed into the mould through unused ports or the mould should be modified accordingly by developing bespoke connectors. In all cases, the sensor is taped on the mould cavity and connected to the measuring unit.

\section{Methodology}

\subsection{Sensor electric field model}

A sensor electric field model was developed using the Finite Element Analysis (FEA) code FLEXPDE [30]. The model is two-dimensional and is able to predict the distribution of the electric field as well as the real and imaginary admittance response at different frequencies. The number of twists per unit length for all sensor configurations considered in this study (500 twists/m) is relatively low not affecting the electric field through the long axis of the sensor. Therefore, a two-dimensional solution operating in the cross section plane of the sensor is appropriate. The aim of the model is to simulate the electric field formed in the gaps between the twisted wires. The illustration in Figure 3 comprises the insulating coating covering the twisted wires and the fluid that surrounds the sensor, which can be either air or resin. Given the symmetry of the configuration in the y direction, only half of the configuration is modelled. Prescribed electric potential boundary conditions were applied to all the nodes at the interface between the electrodes and the coating to represent voltage application by the measuring equipment. 


\subsubsection{Model formulation}

In the case of isotropic medium, the electrostatic problem can be represented by Gauss law including charge conservation as follows [35]:

$$
\nabla \cdot[\varepsilon \nabla \boldsymbol{\Phi}]=0
$$

here $\varepsilon$ is the medium complex permittivity and $\boldsymbol{\Phi}$ is the electric potential, respectively. The electric field can be computed as follows [35]:

$$
\boldsymbol{E}=-\nabla \boldsymbol{\Phi}
$$

The conductive current density is related to the electric field using the following relation:

$$
\boldsymbol{J}=\omega \varepsilon^{\prime \prime} \boldsymbol{E}
$$

where $\varepsilon^{\prime \prime}$ is the dielectric loss.

The complex admittance between the two electrodes of the sensor is calculated by integrating the real and imaginary part of $\boldsymbol{J}$ over the interface between the grounded electrode $(\boldsymbol{\Phi}=0)$ and the insulating coating, respectively:

$$
\boldsymbol{Y}_{i}=\iint_{\boldsymbol{S}} \boldsymbol{J}_{i} d \boldsymbol{S}, i=R e, I m
$$

where $R e$ and $I m$ denote the real and imaginary parts, respectively.

\subsection{Model validation tests}

In order to validate the developed electric field model three lineal sensors were manufactured and tested in air and the experimental data were compared to the corresponding simulation results. All three sensors comprised two uniformly twisted coated 136-AWP solid copper wires with polyurethane enamel coating [36], designated as PU. The twisting was carried out using a hand drill. Two 1.2 meter long wires were is fixed to the workbench using adhesive tape while the other ends were secured in the drill head, ensuring a $1000 \mathrm{~mm}$ span for the twisting. The drill head was rotated 500 times at a uniform rate. Uniformity of twist rate was verified by inspecting random segments of twisted wire. Magnified photographs of $50 \mathrm{~mm}$ lengths along were taken and the number of turns counted. It was found that each 1 meter length of sensor had $500 \pm 7$ turns. This $1.4 \%$ standard deviation is attributed to the tendency of the sensor to un-wind after released from workbench and drill. The diameter of each of the wires was $127 \mu \mathrm{m}$.

The measurements were carried out using a Solartron 1260 Impedance Analyser. Impedance data were acquired over seven frequencies swept logarithmically in the $10 \mathrm{~Hz}-1 \mathrm{MHz}$ range and the corresponding admittance 
response was calculated. For the model validation, the electric permittivity of air was assumed to be equal to that of free space:

$$
\varepsilon_{0}=8.85 \times 10^{-12} \mathrm{~F} / \mathrm{m}
$$

The coating complex electric permittivity used was [37]:

$$
\varepsilon_{c}=2.4 \varepsilon_{0}+0.1 \varepsilon_{0} j
$$

\subsection{Sensor design optimisation}

A multi-objective problem was set up in order to maximise both the real and imaginary sensitivity of the sensor through optimising the sensor geometry and coating material. In this study, the sensor sensitivity was computed using the model admittance values when the sensor is covered with resin or air as follows:

$$
\text { Sens }_{i}=\frac{\text { Yresin }_{i}-\text { Yair }_{i}}{\text { Yair }_{i}} \quad, i=R e, I m
$$

A multi-objective Genetic Algorithm (GA) implemented in C++ [31] was adapted and coupled with the electric field model to solve the problem. Four design parameters were optimised: electrode wire radius $\left(r_{w}\right)$, coating thickness $\left(t_{c}\right)$, coating real permittivity $\left(\varepsilon_{c}^{\prime}\right)$ and coating dielectric loss $\left(\varepsilon_{c}^{\prime \prime}\right)$. Table 1 summarises the range of each of the design parameters which were based on the properties of commercially available wires.

The GA input parameters are shown in Table 2. An angular frequency $(\omega)$ of $1000 \mathrm{rads} / \mathrm{s}$ was used in all optimisation runs. For these sensitivity calculations, the resin dielectric constant was defined as follows based on the order of magnitude of complex dielectric permittivity reported in [38]:

$$
\varepsilon_{\text {resin }}=1 \times 10^{-12}+1 \times 10^{-12} \mathrm{j} \mathrm{F/m}
$$

Equations (6) and (7) were used to represent air and coating electric permittivity, respectively.

\subsection{Sensor validation trials}

The evaluation of the sensors was carried out during RTM processing of two carbon fibre/epoxy flat panels; one manufacturing trial was carried out using an industrial type press clamping tool and one was performed in a lab RTM tool with a glass top plate. The press clamping trial was performed in order to assess the sensor response under RTM conditions used in industrial practice, whilst the glass top tool trial was carried out to investigate the accuracy of the lineal flow sensors against an independent visual measurement of the flow front position. In both cases the resin system was the two-component epoxy Hexcel HexFlow® RTM6-2 [39] and the reinforcement material was the 5H satin weave carbon fabric Hexcel HexForce® G0926 [40]. The details of the 
wires used to produce the twisted sensors for these experiments are reported in Table 3. Sensor wires were industrially twisted at AGTEKS Ltd [45] using a DirectTwist 2D6 with a twisting pitch of 500 twists/m. The press clamping trial was carried out using a P.J. Hare 100T hydraulic press (Figure 4) with a consolidation pressure of 7 bar. The mould was of circular shape with a radius of $225 \mathrm{~mm}$. Resin was injected from a hole of $30 \mathrm{~mm}$ diameter located in the centre of the top half of the mould. The preform comprised 8 layers using a $\left[(0 \mathrm{~F})_{8}\right]$ lay-up with a radius of $225 \mathrm{~mm}$ and a final thickness of $3.1 \mathrm{~mm}$. The fibre volume fraction was $54 \%$. An injection pressure of 3 bar and injection temperature of $80^{\circ} \mathrm{C}$ were used. The filling was carried out at a constant temperature of $120^{\circ} \mathrm{C}$. The cure step occurred after the completion of the filling by heating up to $180^{\circ} \mathrm{C}$ at a rate of $1^{\circ} \mathrm{C} / \mathrm{min}$ and remaining at this temperature for two hours. Four lineal flow sensors using Ny/PU, PTFE, PILD and PI- HD twisted wires of different lengths were mounted at different positions at the lower part of the mould (Figures 5a and 5b). In addition, two woven cure sensors made using Ny/PU and PI-LD twisted wires were placed on the lower tool surface. The cure sensors were woven on a thin $20 \mathrm{~g} / \mathrm{m}^{2}$ E-glass veil. The weaving was performed on a rectangular grid marked on the glass veil of overall dimensions of $35 \mathrm{~mm} \times 35 \mathrm{~mm}$ with ten columns and rows (Figure 6). As a result, both cure sensors were made using $0.8 \mathrm{~m}$ of twisted wires. All sensors were connected to the ADVISE-DETA DETA SCOPE [46] monitoring system. Dielectric data of capacitance, resistance, impedance and admittance were acquired over fifteen frequencies swept logarithmically in the $22 \mathrm{~Hz}$ - $104.2 \mathrm{kHz}$ range. A k-type thermocouple was attached onto the tool and connected to the data acquisition system. In this case the mould was adapted accordingly, and bespoke connectors were developed to mount the sensor in the mould.

A rectangular tool with dimensions $900 \mathrm{~mm} \times 340 \mathrm{~mm} \times 3.3 \mathrm{~mm}$ was used in the case of the glass top RTM trial. The preform comprised nine layers with a $\left[(0 \mathrm{~F} / 90 \mathrm{~F})_{2} / 0 \mathrm{~F} /(90 \mathrm{~F} / 0 \mathrm{~F})_{2}\right]$ lay-up sequence with overall dimensions of $800 \mathrm{~mm} \times 340 \mathrm{~mm} \times 3.3 \mathrm{~mm}$. In this case the fibre volume fraction was $57 \%$. The filling was carried out under isothermal conditions at $120^{\circ} \mathrm{C}$ with an injection pressure of 1 bar and resin temperature of $80^{\circ} \mathrm{C}$. The cure step was carried out after the end of the filling at $160^{\circ} \mathrm{C}$ for two hours using a heating ramp of $1.5^{\circ} \mathrm{C} / \mathrm{min}$. In this case a lineal flow sensor made of PI-LD twisted wire was used to monitor the flow. The sensor was placed in the centre of the RTM tool with total length of $700 \mathrm{~mm}$ (Figure 7) and was fed in the mould via an unused port. A k-type thermocouple was also placed on the tool. The consolidation pressure applied through a clamping system as shown in Figure 8 was approximately 4 bar. All measurements were carried out using a Solartron 1260 Impedance Analyser. Impedance data were acquired over seven frequencies and swept logarithmically in the $1 \mathrm{kHz}-1 \mathrm{MHz}$ range. The analyser was connected to a computer using an 
IEEE interface. An in-house code developed using LabVIEW was used for data acquisition. A toughened glass top plate was used to allow visual monitoring of the flow front for validation purposes and a digital camera acquired images and a video during the filling process. Figure 8 depicts the experimental set-up and the data acquisition system. 


\section{Results and discussion}

\subsection{Electric field model}

Figure 9 illustrates the experimental data and model results for the response of sensors in air presented as real and imaginary admittance for the frequency range. The experimental response shows that the system behaves in a capacitive manner. This is reproduced by the model in terms of both differences in magnitude between the real and imaginary part of the admittance and dependence on frequency. The satisfactory correlation between the simulation results and the experimental data implies that the developed model can capture the sensor electric field accurately. Furthermore, these results demonstrate that the assumption of two- dimensional electric field made in this study is appropriate.

In moulding, the component is subjected to consolidation pressure during the manufacturing process. Therefore, carbon fibres can be locally deformed and conform around the sensor penetrating in the gaps between the twisted wires. This can potentially affect the sensor electric field and in turn its sensitivity. The effect of carbon fibre penetration on the response of the sensor in contact with the dry fabric was investigated using the sensor electric field model (Figure 10). The sensor configuration described in section 3.2 was modelled whilst the carbon reinforcement was assumed to reach an isopotential condition due to its conductive character. In practice, this is achieved in the model by assuming a very high permittivity value ( $110^{-3} \mathrm{~F} / \mathrm{m}$ in this case). Models with a carbon penetration depth ranging from 0 to $50 \mu \mathrm{m}$ ( 0 to $40 \%$ of the wire diameter) with an increment of $5 \mu \mathrm{m}$ were executed. An angular frequency $\omega$ of $1000 \mathrm{rads} / \mathrm{s}$ was used in all cases. Figure 11 illustrates the capacitance determined by the model as a function of the carbon reinforcement depth of penetration. Carbon penetration in the area between wires has a considerable effect on sensor response for values above $30 \mu \mathrm{m}$, which in this case is more than half of the total wire radius. Below these values, carbon penetration does not play a role in the signal, implying that its influence can be neglected. This is due to the fact that the electric field is mainly concentrated at the tip of the gap between the twisted wires, as observed in Figure 12, and thus any field interruption occurring away from the tip has a negligible effect on the sensor response. These findings imply that sensor sensitivity is not affected by the areal density of the fabric given that fabrics with different areal density would present different levels of fibre penetration. Therefore, the sensor electric field can be modelled accurately without considering the presence of carbon reinforcement. 


\subsection{Sensor design/optimisation}

The results of sensor design/optimisation are summarised in Table 4. The optimisation results converged to a single solution implying that the optimisation problem of this study can be captured fully by a single objective. Considering the range of the design variables reported in Table 1, the optimal design involves a maximum value for the wire diameter, minimum value for the coating thickness, maximum value for the coating permittivity and a relatively low value for the coating loss. This implies that sensor sensitivity increases with increasing wire diameter, decreasing coating thickness and with using a coating with high dielectric permittivity and relatively low dielectric loss. A greater wire diameter increases the area of the gaps formed between the twisted wires resulting in higher capacitance and in turn in higher sensitivity. Lower coating thickness reduces the distance between the two conductive wires leading to higher capacitance. High coating electric permittivity and low coating dielectric loss strengthens the formed electric field increasing the sensor capacitance leading to higher sensitivity.

A sensitivity analysis was carried out to investigate the relative influence of each of the different design parameters on sensor responsiveness. The focus was on the wire radius and coating thickness given that in practice the range of coating materials that are available for the application is relatively limited. In terms of coating selection, the priority is to ensure that the temperature rating of the material suits the sensor requirements for operation during the flow and curing stages. Eight wire radiuses were studied varying from 10 $\mu \mathrm{m}$ to $150 \mu \mathrm{m}$ with an increment of $20 \mu \mathrm{m}$. In this case, the coating thickness was set to $5 \mu \mathrm{m}$. Similarly, eight coating thicknesses were investigated varying from $5 \mu \mathrm{m}$ to $40 \mu \mathrm{m}$ using an increment of $5 \mu \mathrm{m}$ with wire radius set at $58.5 \mu \mathrm{m}$. In all cases the coating permittivity was defined using Eq. (7) and $\omega$ was $1000 \mathrm{rads} / \mathrm{s}$.

Figure 13 summarises the sensitivity analysis results. The sensitivity of real and imaginary admittance shows a non-linear dependence on wire radius and coating thickness. The dependence is increasing for the wire radius and decreasing for coating thickness following the trends identified in the optimisation. Sensitivity increases considerably by increasing wire radius up to $70 \mu \mathrm{m}$ whilst a moderate increase is shown as wire radius increases from $70 \mu \mathrm{m}$ to $90 \mu \mathrm{m}$. For wire radius greater than $90 \mu \mathrm{m}$ a slow increase is observed. Sensitivity decreases significantly with increasing coating thickness up to $25 \mu \mathrm{m}$. A moderate decrease is presented as the coating thickness increases from $25 \mu \mathrm{m}$ to $40 \mu \mathrm{m}$. Similarly to the wire radius, the occurrence of a plateau occurs at high coating thicknesses. The upper limit for the radius is dictated by the sensor disturbance to the architecture of the fabric. Very high radiuses can introduce significant defects, thus the goal here is to increase the radius as 
much as possible while at the same time keep it at an acceptable level in terms of sensor intrusiveness. In terms of coating thickness the lower limit is strictly dictated by what is commercially available.

These findings contributed to the selection of the wires used in this study (Table 3), which were chosen so that they match as much as possible the optimisation results in terms of wire geometry and coating material properties within the range of wires available in the market.

\subsection{Flow monitoring}

Figure 14 presents the response of the PI-LD and Ny/PU lineal flow sensors during the RTM process under 7 bar consolidation pressure performed in a press. The sensor response represented as real length for the NY/PU and PI-LD sensors was calculated using Eq. (1). As Eq. (1) shows, the flow length estimated based on the admittance measurements is the ratio of two complex numbers. In ideal conditions, in which the state of the material, the environmental conditions and sensor field are identical across the full length of the sensor, the numerator and denominator of the ratio are in phase resulting in a negligible imaginary part of the estimated length. Deviations from these ideal conditions, as well as experimental noise, lead to higher values of imaginary length. Therefore, the sensor response provides a direct indication of measurement and corresponding analysis errors [1]. Both sensors measured a parabolic flow front evolution, with the flow reaching the end of the PI-LD sensor after about $3 \mathrm{~min}$ and the end of the Ny/PU sensors after about $4 \mathrm{~min}$. This is due to the fact that the PILD was mounted along the warp direction and the Ny/PU was placed along the $45^{\circ}$ direction (Figure $5 \mathrm{~b}$ ), which has lower permeability. In the case of the PI-LD sensor the imaginary length was less than $1.5 \%$ of the total length, whilst the imaginary length of the Ny/PU sensor was slightly higher with values varying below $2 \%$ of the total length of the sensor. This implies that these sensors can offer high-quality measurements as the response of the sensor is consistent with the assumptions of uniformity in material properties, sensor and field geometry. These results show that the Ny/Pu and PI-LD sensors are robust under industrial RTM conditions reaching maximum pressure of 7 bar in the moulding in contact with the conductive reinforcement. The PTFE and PI-HD flow sensor presented poor results due to lack of robustness of the coating at the temperatures/pressures of the trial resulting in electrical shorting with the carbon and/or metal tool. This is attributed to the total diameter of these two wires. Albeit increasing wire diameter results in better sensor sensitivity, twisting of high diameter wires can introduce significant stress, which in combination with the application of consolidation pressure can damage the insulating coating. This in turn results in electrical shorting in contact with a conductor such as carbon fibres. 
Figure 15 shows the flow front at two instances during the glass top RTM trial. No substantial race tracking on the sides of the mould is observed. The flow pattern is uniform at the centre of the mould where the sensor was placed. Given the low thickness of the flat panel $(3.3 \mathrm{~mm})$ it is expected that through thickness flow front variations are negligible. Figure 16 depicts the response of the PI-LD lineal flow sensor against the visual flow front measurements. The sensor response, represented as real length using Eq. (1), is in very good agreement with the measured behaviour of the flow front during the whole duration of the filling. The error between the sensor response and the actual flow front position is below 5\%. The imaginary length varies between $-4 \mathrm{~mm}$ and $3 \mathrm{~mm}$ which is below $0.6 \%$ of the overall length, indicating a high-quality measurement. These findings prove that the sensor gives an accurate measurement of the flow front position. The permeability values computed based on the sensor results for the first $3 \mathrm{~min}$ of data acquisition in the two trials, using a constant viscosity of $24 \mathrm{mPa} . \mathrm{s}$ at the injection temperature of $120^{\circ} \mathrm{C}$ [47], are $6.5 \times 10^{-12}$ and $1.2 \times 10^{-11} \mathrm{~m}^{2}$ for the central injection and the linear injection experiments. Both values are in good agreement with results in the literature for the same fabric $[48,49]$.

\subsection{Cure monitoring}

Figure 17 depicts the evolution of imaginary impedance as measured by the PI-LD woven cure sensor during the RTM process under 7 bar consolidation pressure. In addition, the degree of cure evolution calculated using the cure kinetics model detailed in [50] and the temperature profiles acquired during the trials are presented, as well as the evolution of specific heat capacity as predicted by an appropriate constitutive model for the resin system [51]. The response of the cure sensor at a fixed frequency $(8.2 \mathrm{kHz})$ is sensitive to the state of the cure and correlates well with the degree of cure predicted by the cure kinetics model. Although impedance signals are highly sensitive to frequency, meaning that in order to obtain a cure metric from monitoring results it is necessary to identify and follow frequency independent features of the spectrum, such as the imaginary impedance maximum, the impedance trace obtained by the sensor is typical of a curing signal. This result highlights the ability of the cure sensor to monitor the degree of cure evolution during the process. Imaginary impedance spectroscopy can also be used to identify the vitrification point of the resin during the reaction. This is due to the influence of dipolar (alpha) relaxation, which is manifested as a secondary shoulder in the evolution of imaginary impedance at a fixed frequency [34]. The evolution of imaginary impedance in Figure 18 involves a second step, which marks occurrence of vitrification. The step occurs at about 93 min. 
Figure 18 illustrates the cure monitoring results obtained by the PI-LD lineal flow sensor. It can be observed that the flow sensor acquires appropriate cure signals. Similarly to the case of the cure sensor, there is a two step behaviour, with the first step governed by cure and its influence on the mobility of migrating charges, and the second step being a signature of the occurrence of vitrification. Vitrification in this case is identified by the second step at about $100 \mathrm{~min}$, a value close to the occurrence of vitrification in the specific heat capacity curve at about $108 \mathrm{~min}$. The two sensors present some differences in response with both cure and vitrification events identified slightly later, by about 7-8 min, by the lineal flow sensor. This is attributed to potential differences in the thermal profiles followed at the location of the cure sensor and in the material in contact with the lineal sensor.

The utilisation of the sensor setups investigated here for identification of vitrification is detailed further in Figure 19. Figure 19a presents the imaginary impedance measured by the flow sensor at various frequencies in the time interval in which vitrification is observed. The impedance signals have been shifted by subtracting the value of impedance at the beginning of the second step to allow comparison and identification of trends with respect to frequency dependence. It can be observed that the curves shift to greater times as the frequency decreases, starting from an inflection point at about $97 \mathrm{~min}$ at $104.2 \mathrm{kHz}$ to about $102 \mathrm{~min}$ at $1.5 \mathrm{kHz}$. This behaviour is expected as the glass transition is a frequency dependent phenomenon, with lower frequencies implying slower excitation corresponding to vitrification occurring at slightly greater cross linking density. This phenomenon is depicted in Figure 19b, which presents the time of the inflection point corresponding to vitrification as a function of measurement frequency for both the lineal and woven PI sensors. The behaviour obtained by the two sensors is similar, with the logarithm of the time of alpha relaxation decreasing linearly with increasing frequency. The log-linear interpolation curves can be used to estimate the vitrification time corresponding to $0.1 \mathrm{~Hz}$, which is the frequency of Modulated Differential Scanning Calorimetry (MDSC) specific heat capacity measurements carried out using an amplitude of $1{ }^{\circ} \mathrm{C}$ and a period of $60 \mathrm{~s}$, such as those reported in [46]. The vitrification times obtained using this procedure are 109 and 112 min for the cure and flow sensors respectively, a result that is very close to the vitrification step at 108 min observed in the specific heat capacity curve. Therefore, it can be concluded that the sensors developed in this work can be used to probe in detail relaxation effects and identify the occurrence of vitrification in the curing carbon composite.

The Ny/PU woven cure sensor was not able to capture the cure reaction yielding measurements of poor quality. This is attributed to the fact that the maximum operating of this sensor is around $160^{\circ} \mathrm{C}[40]$ rendering this material not suitable for cure monitoring during high temperature RTM processes. Overall, it was shown that 
both the lineal flow and cure sensor made of PI-LD twisted wires were the most robust choices compared to the other configurations considered in this study. This sensor introduces negligible disturbance to the fibre architecture given that its dimensions are of a scale similar of resin rich channels observed in composite parts. It should be noted that for typical laminates thicknesses of 5-20 mm the disturbance introduced by the sensor corresponds to $0.75-3 \%$ of the thickness, which if translated to a change in fibre volume fraction for high quality fabrics can cause local permeability differences in the range of 1-5\%. Given the very limited width of the region affected this will influence the local flow conditions during the filling stage.

\section{Conclusions}

A process monitoring dielectric sensor comprising insulated copper wires was optimised and implemented in industrial conditions in the manufacturing of carbon reinforced composites. To simulate the dielectric response of the sensor, an electric field model was developed and validated against experimental data. The sensor design was optimised in terms of wire radiuses, coating thicknesses and coating materials by coupling the electric field model with a multi-objective GA. Validation RTM tests in industrial conditions demonstrated the accuracy and robustness of both the lineal flow and woven cure sensor in industrial conditions.

The lineal character of the flow sensor means that the signals obtained correspond to the length of the sensor covered by resin. In cases of complex non monotonic flow patterns multiple sensors in conjunction with an appropriate analysis procedure are required to uncover the front position. The woven cure sensor can provide valuable information around the degree of cure development and vitrification point in industrial processing of carbon reinforced composites. Furthermore, the flow sensors can be used to monitor the cure over a wide area of the component, while also being capable to obtain a detailed and accurate signature of vitrification. In addition, the flow sensors can be used in the case of thermoplastic composites manufactured by LCM, given that the sensors can capture flow regardless of the fluid. In the case of thick components multiple sensors mounted between different layers can be used. The methodologies presented here imply that the sensors are sacrificial as they are embedded to the composite part. For reusability reasons appropriate cavities can be formed into the mould where the sensors can be mounted.

It was clearly indicated that the sensor withstands RTM level pressures within an industrial environment. Furthermore, its placement between the carbon fabric and the metallic mould tested in this study is the worst case scenario in terms of potential damage to the coating material as well as potential electrical interference by conductors. In the case of high specification aerospace applications, the disturbance in fabric architecture 
introduced by the sensor can be a limitation. Utilisation of thinner wires reduces the sensor sensitivity; however it can enhance the non-intrusive character of the technology. In addition, the design of the sensor allows direct incorporation onto fabrics, contributing towards the development of smart composites with process monitoring capabilities.

\section{Acknowledgements}

This work was supported by the High Value Manufacturing Catapult through the Technology Pull-Through fund at the National Composites Centre UK. Data underlying this study can be accessed through the Cranfield University repository at https://doi.org/10.17862/cranfield.rd.12563276.

\section{References}

[1] Skordos AA, Karkanas PI, Partridge IK. A dielectric sensor for measuring flow in resin transfer moulding. Measurement Science and Technology. 2000;11(1):25.

[2] Skordos AA, Partridge IK. Dielectric flow sensing in resin transfer moulding of carbon fibre reinforced composites. Plastics, rubber and composites. 2000;29(8):391-4.

[3] Dominauskas A, Heider D, Gillespie JW. Electric time-domain reflectometry distributed flow sensor. Compos Part A Appl Sci Manuf 2007;38(1):138-46.

[4] Barooah P, Sun J. Lineal sensors for flow sensing in liquid injection molding of composites. J Mater Process Manuf Sci 1999;7(4):416-27.

[5] Luthy T, Ermanni P. Linear direct current sensing system for flow monitoring in liquid composite moulding. Compos - Part A Appl Sci Manuf 2002;33(3):385-97.

[6] Kueh SRM, Advani SG, Parnas RS. Sensor placement study for online flow monitoring in liquid composite molding. Polym Compos 2000;21(3):436-49.

[7] Gupta N, Sundaram R. Fiber optic sensors for monitoring flow in vacuum enhanced resin infusion technology (VERITy) process. Compos Part A Appl Sci Manuf 2009;40(8):1065-70.

[8] Lekakou C, Cook S, Deng Y, Ang TW, Reed GT. Optical fibre sensor for monitoring flow and resin curing in composites manufacturing. Compos Part A Appl Sci Manuf 2006;37(6):934-8.

[9] Lynch K, Hubert P, Poursartip A. Use of a simple, inexpensive pressure sensor to measure hydrostatic resin pressure during processing of composite laminates. Polym Compos 1999;20(8):581-93. 
[10] Amico S, Lekakou C. An experimental study of the permeability and capillary pressure in resin-transfer moulding. Compos Sci Technol 2001;61(13):1945-59.

[11] Di Fratta C, Klunker F, Ermanni P. A methodology for flow-front estimation in LCM processes based on pressure sensors. Compos Part A Appl Sci Manuf 2013; (1):1-11.

[12] Fernando GF, Liu T, Crosby P, Doyle C, Martin A, Brooks D, et al. A multi-purpose optical fibre sensor design for fibre reinforced composite materials. Meas Sci Technol 1997;8(10):1065-79.

[13] Mijović J, Andjelić S. Monitoring of reactive processing by remote mid infra-red spectroscopy. Polymer 1996;37(8):1295-303.

[14] Cossins S, Connell M, Cross B, Winter R, Kellar J. In situ near-IR cure monitoring of a model epoxy matrix composite. Appl Spectrosc 1996;50(7):900-5.

[15] Mijovic J, Andjelic S. A study of reaction kinetics by near-infrared spectroscopy. 1. Comprehensive analysis of a model epoxy/amine system. Macromolecules 1995;28(8):2787-96.

[16] Mijović J, Andjelić S. In situ real-time monitoring of reactive systems by remote fibre-optic near-infra-red spectroscopy. Polymer 1995;36(19):3783-6.

[17] Levy RL, Schwab SD. Monitoring the composite curing process with a fluorescencebased fiber-optic sensor. Polym Compos 1991;12(2):96-101.

[18] Stroeks A, Shmorhun M, Jamieson AM, Simha R. Cure monitoring of epoxy resins by excimer fluorescence. Polymer 1988;29(3):467-70.

[19] Wang FW, Lowry RE, Fanconi BM. Novel fluorescence method for cure monitoring of epoxy resins. Polymer 1986;27(10):1529-32.

[20] Liu YM, Ganesh C, Steele JPH, Jones JE. Fiber optic sensor development for realtime in-situ epoxy cure monitoring. J Compos Mater 1997;31(1):87-102.

[21] Maistros GM, Partridge IK. Monitoring autoclave cure in commercial carbon fibre/ epoxy composites. Compos Part B Eng 1998;29(3):245-50.

[22] Bellucci F, Valentino M, Monetta T, Nicodemo L, Kenny J, Nicolais L, et al. Impedance spectroscopy of reactive polymers. 1. J Polym Sci Part B Polym Phys 1994;32(15):2519-27.

[23] Mijović J, Andjelic S, Fitz B, Zurawsky W, Mondragon I, Bellucci F, et al. Impedance spectroscopy of reactive polymers. 3. Correlations between dielectric, spectroscopic, and rheological properties during cure of a trifunctional epoxy resin. J Polym Sci Part B Polym Phys 1996;34(2):379-88. 
[24] Day DR. Dielectric determination of cure state during non-isothermal cure. Polym Eng Sci 1989;29(5):334-8.

[25] Levita G, Livi A, Rolla PA, Culicchi C. Dielectric monitoring of epoxy cure. J Polym Sci Part B Polym Phys 1996;34(16):2731-7.

[26] McIlhagger A, Brown D, Hill B. Development of a dielectric system for the on-line cure monitoring of the resin transfer moulding process. Compos Part A Appl Sci Manuf 2000;31(12):1373-81.

[27] Maistros GM, Partridge IK. Dielectric monitoring of cure in a commercial carbonfibre composite. Compos Sci Technol 1995;53(4):355-9.

[28] Mijović J, Kenny JM, Maffezzoli A, Trivisano A, Bellucci F, Nicolais L. The principles of dielectric measurements for in situ monitoring of composite processing. Compos Sci Technol 1993;49(3):277 90.

[29] Tifkitsis KI, Skordos AA. A novel dielectric sensor for process monitoring of carbon fibre composites manufacture. Compos Part A Appl Sci Manuf 2019;123:180-189.

[30] FlexPDE 7®, FlexPDE Help. https://www.pdesolutions.com/help/index.html, 2019.

[31] Struzziero G, Skordos AA. Multi-objective optimisation of the cure of thick components, Compos Part A Appl Sci Manuf 2017, 93: 126-136

[32] Mijovic J, Yee CW. Use of complex impedance to monitor the progress of reactions in epoxy/amine model systems. Macromolecules 1994;27(25):7287-93.

[33] Skordos AA, Partridge IK. Determination of the degree of cure under dynamic and isothermal curing conditions with electrical impedance spectroscopy. J Polym Sci Part B Polym Phys 2004;42(1):146-54. [34] Andjelic S, Mijovic J, Bellucci F. Impedance spectroscopy of reactive polymers. 5. Impedance as a measure of chemical and physical changes in glass formers, J Polym Sci Part B Polym Phys 1998;36(4):641-653 [35] Von Guggenberg PA, Zaretsky MC. Estimation of one-dimensional complex-permittivity profiles: a feasibility study. J Electrost 1995;34(2-3):263-77.

[36] Vishay Micro Measurements, 136-AWP solid wire, www.vishaypg.com 2018.

[37] Velayutham TS, Abd Majid WH, Gan SN. Dielectric behaviour of polyurethane coatings derived from palm oil oleic acid-based polyols-A renewable resource. J. Oil Palm Res. 2012;24:1260-1266.

[38] Karkanas PI. Cure modelling and monitoring of epoxy/amine resin systems. PhD Thesis, Cranfield University 1998.

[39] Hexcel HexFlow ${ }^{\circledR}$ RTM6-2 $180^{\circ} \mathrm{C}$ bi-component epoxy system for Resin Transfer Moulding and Infusion technologies Product Data, www.hexcel.com 2019. 
[40] Hexcel HexForce® G0926, Product Data, www.hexcel.com 2018.

[41] Vishay Micro Measurements, S02853-0000 solid wire, www.vishaypg.com, 2019.

[42] Advent Research Materials Ltd, CU515018 copper insulated wire, https://www.advent-rm.com, 2019.

[43] Vishay Micro Measurements, 134-AWQ 500 solid wire, www.vishaypg.com, 2019.

[44] Advent Research Materials Ltd, CU750618 copper insulated wire, https://www.advent-rm.com, 2019.

[45] AGTEKS Ltd, http://www.agteks.com/page/main-page, 2019.

[46] ADVISE-DETA Ltd, https://www.advise-deta.com/en/pages/deta-scope-cpms, 2019.

[47] Tifkitsis KI, Skordos AA. Real time uncertainty estimation in filling stage of RTM process. Polymer Composites 2020, in print.

[48] Friedrich M, Exner W, Wietgrefe M. Sensitivity analysis of influencing factors on impregnation process of closed mould RTM. CEAS Aeronautical Journal. 2011 Dec 1;2(1-4):195-202.

[49] Stamatopoulos G, Modi D, Lira C, Pantelelis N, Stojkovic M. Development of a procedure for accurate simulation of the resin transfer moulding process.. In: Proceedings of the 18th European Conference of Composite Materials, 24-28 June 2018.Athens, Greece.

[50] Mesogitis TS, Skordos AA, Long AC. Stochastic simulation of the influence of cure kinetics uncertainty on composites cure. Composites Science and Technology. 2015 Apr 6;110:145-51.

[51] Struzziero G, Remy B, Skordos AA. Measurement of thermal conductivity of epoxy resins during cure. J Appl Polym Sci 2018;47015(8):1-10. 


\section{Figure captions}

Figure 1. Schematic representation of twisted wire lineal flow sensor [29].

Figure 2. Twisted wire woven cure sensor [29].

Figure 3. Sensor electric field model for sensitivity optimisation.

Figure 4. RTM set-up for press clamping trials.

Figure 5. Ny/PU, PTFE, PI-LD and PI-HD flow sensors location at the lower tool surface in the press clamping trial under 7 bar consolidation pressure: a) placement on tool; b) schematic.

Figure 6. Twisted woven sensor made of Ny/PU twisted wire.

Figure 7. PI-LD flow sensor placed at the centre of the lower tool surface of the glass top RTM.

Figure 8. Experimental set-up used for glass top RTM trial.

Figure 9. Real a) and b) imaginary admittance spectra of PU sensor in air.

Figure 10. Sensor electric field model with carbon reinforcement indentation.

Figure 11. Effect of carbon indentation on sensor response.

Figure 12. Real electric field distribution of sensor in air. Colour map units are $\mathrm{V} / \mathrm{m}$.

Figure 13. Sensitivity analysis: wire radius a), coating thickness b).

Figure 14. Dielectric flow measurement at $104.2 \mathrm{kHz}$ during RTM process with 7 bar clamping pressure, using a PI-LD lineal flow sensor a), and Ny/PU lineal flow sensor b).

Figure 15. Visual flow front evolution during glass top RTM trial under 4 bar clamping pressure: 3.9 min a), $44.8 \mathrm{~min} b)$.

Figure 16. Comparison of visual with dielectric flow measurement at $1 \mathrm{MHz}$ using PI-LD- lineal flow sensor during glass top RTM trial under 4 bar clamping pressure.

Figure 17. PI-LD woven cure sensor response during the curing stage of the RTM process at 7 bar clamping pressure: imaginary impedance evolution at $8.2 \mathrm{kHz}$ and comparison with degree of cure development and the evolution of specific heat capacity.

Figure 18. PI-LD lineal flow sensor response during the curing stage of the RTM process at 7 bar clamping pressure: imaginary impedance evolution at $8.2 \mathrm{kHz}$ and comparison with degree of cure development and the evolution of specific heat capacity.

Figure 19. Identification vitrification by the PI-LD sensors: a) Shifted imaginary impedance spectra in the vitrification time interval; b) dependence of time of inflection point on the frequency of the impedance measurement. 
Table 1. Design parameters range.

\begin{tabular}{cc}
\hline Design parameter & Range \\
\hline$r_{w}[\mu \mathrm{m}]$ & $40-215$ \\
$t_{c}[\mu \mathrm{m}]$ & $2-40$ \\
$\varepsilon_{c}^{\prime}[\mathrm{F} / \mathrm{m}]$ & $1.7710^{-11}-1.7710^{-10}$ \\
$\varepsilon_{c}^{\prime \prime}[\mathrm{F} / \mathrm{m}]$ & $8.8510^{-15}-4.4210^{-12}$ \\
\hline
\end{tabular}

Table 2. GA input parameters.

\begin{tabular}{cc}
\hline GA input parameter & Value \\
\hline Number of generations & 50 \\
Individuals per population & 60 \\
Individuals per reproduction & 48 \\
Elite individuals & 4 \\
Size of Pareto front & 30 \\
Mutation probability & 0.005 \\
Cross-over probability & 0.5 \\
\hline
\end{tabular}


Table 3. Details of copper wires used in RTM trials.

\begin{tabular}{cccccc}
\hline Designation & Coating type & $\begin{array}{c}\text { Coating } \\
\text { thickness }(\mu \mathrm{m})\end{array}$ & $\begin{array}{c}\text { Wire diameter } \\
(\mu \mathrm{m})\end{array}$ & Commercial name & Supplier \\
\hline Ny/PU & $\begin{array}{c}\text { Nylon/polyurethane } \\
\text { enamel }\end{array}$ & 5.0 & 58.5 & S02853-0000 [41] & $\begin{array}{c}\text { Vishay Micro } \\
\text { Measurements }\end{array}$ \\
PTFE & PTFE & 40.0 & 125.0 & CU515018 [42] & $\begin{array}{c}\text { Advent Research } \\
\text { Materials Ltd }\end{array}$ \\
PI-LD & Polyimide & 5.0 & 75.0 & 134-AWQ 500 [43] & $\begin{array}{c}\text { Vishay Micro } \\
\text { Measurements }\end{array}$ \\
PI-HD & Polyimide & 11.5 & 127.0 & CU750618 [44] & $\begin{array}{c}\text { Advent Research } \\
\text { Materials Ltd }\end{array}$ \\
\hline
\end{tabular}

Table 4. Sensor design /optimisation results.

\begin{tabular}{cc}
\hline Design parameter & Value \\
\hline$r_{w}[\mu \mathrm{m}]$ & 215 \\
$t_{c}[\mu \mathrm{m}]$ & 2 \\
$\varepsilon_{c}^{\prime}[\mathrm{F} / \mathrm{m}]$ & $1.7710^{-10}$ \\
$\varepsilon_{c}^{\prime \prime}[\mathrm{F} / \mathrm{m}]$ & $8.8510^{-14}$ \\
\hline
\end{tabular}




\section{Insulation}

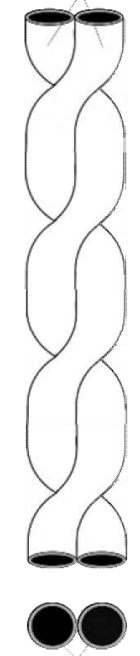

Copper wire

Figure 1. Schematic representation of twisted wire lineal flow sensor [29].

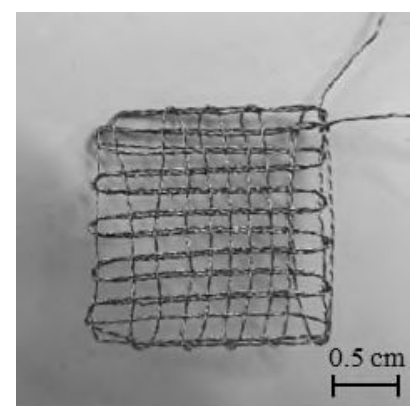

Figure 2. Twisted wire woven cure sensor [29]. 


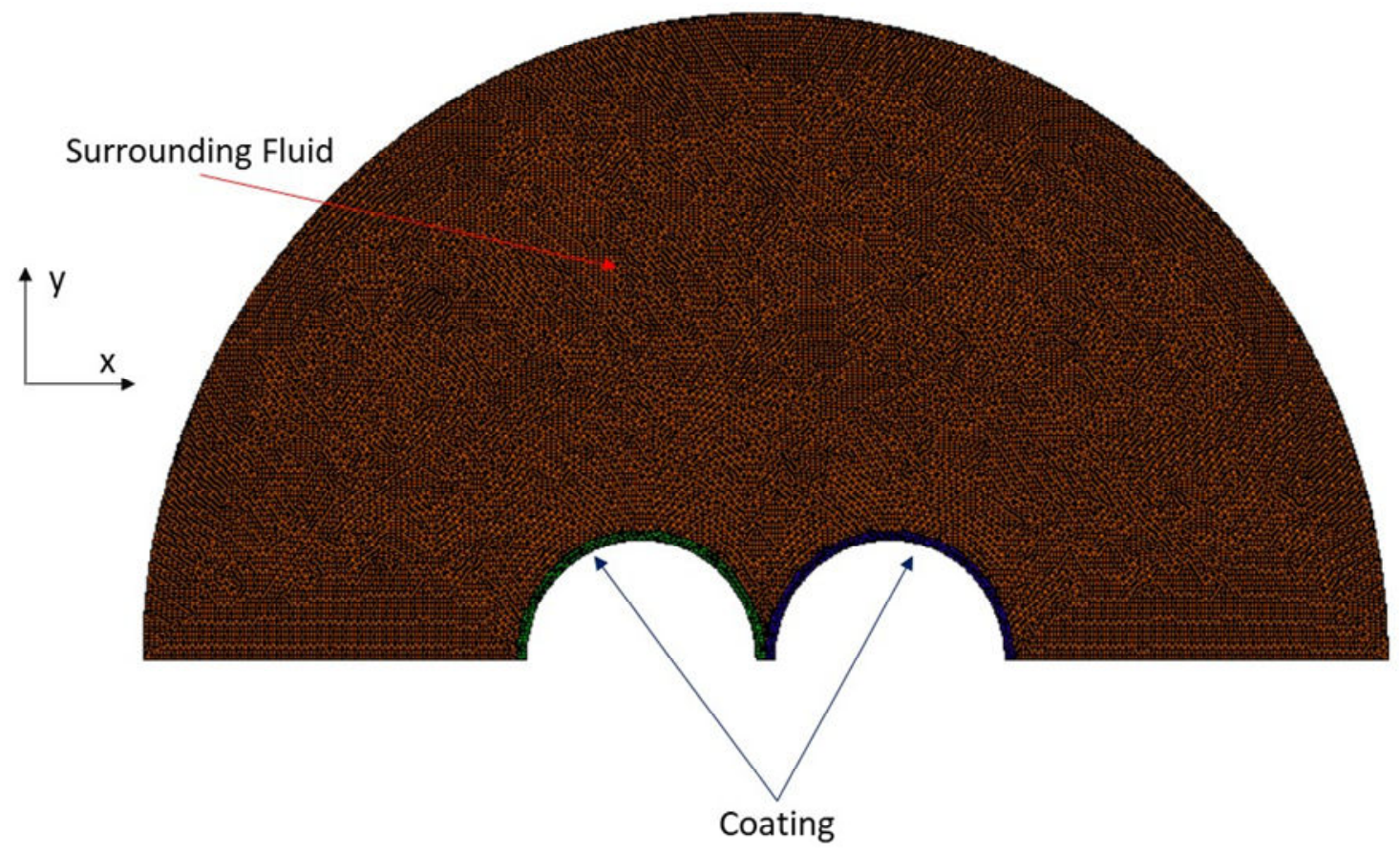

Figure 3. Sensor electric field model for sensitivity optimisation.

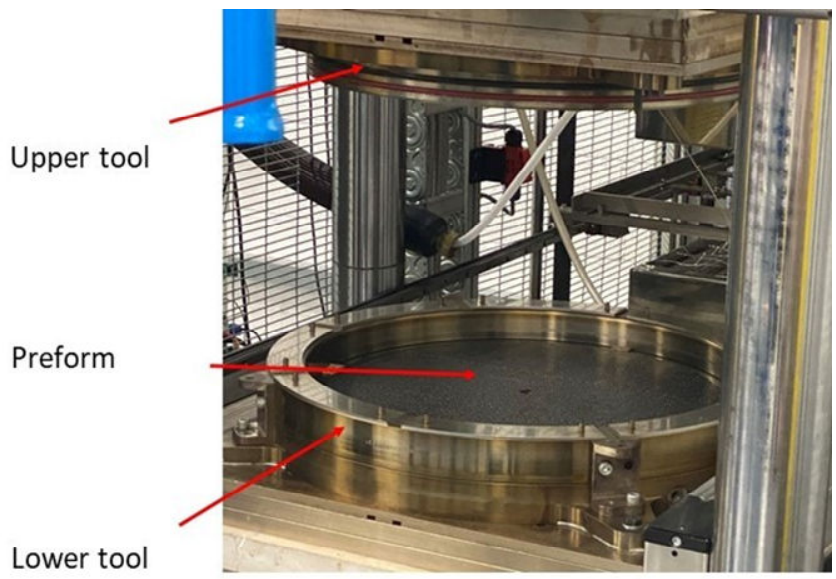

Figure 4. RTM set-up for press clamping trials. 
a)

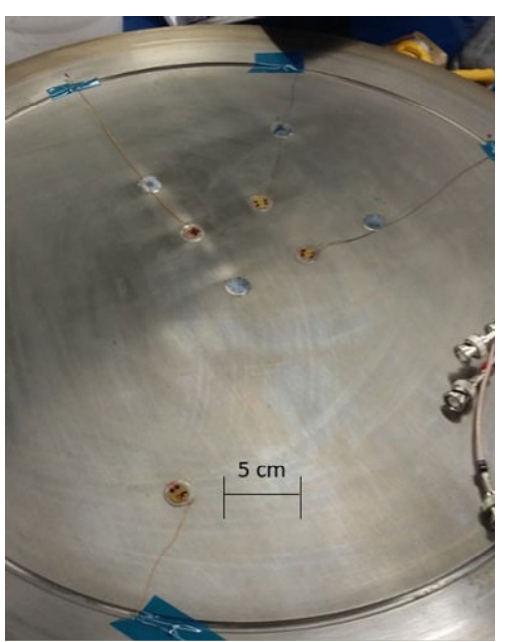

b)

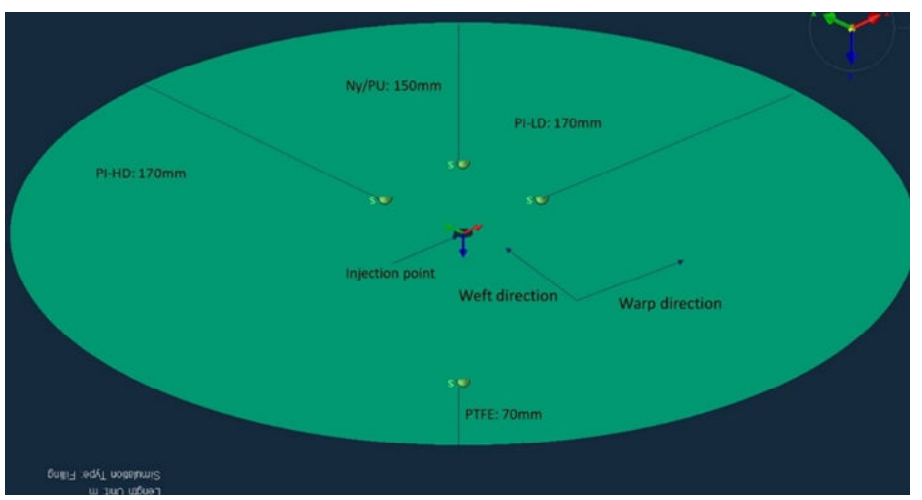

Figure 5. Ny/PU, PTFE, PI-LD and PI-HD flow sensors location at the lower tool surface in the press clamping trial under 7 bar consolidation pressure: a) placement on tool; b) schematic.

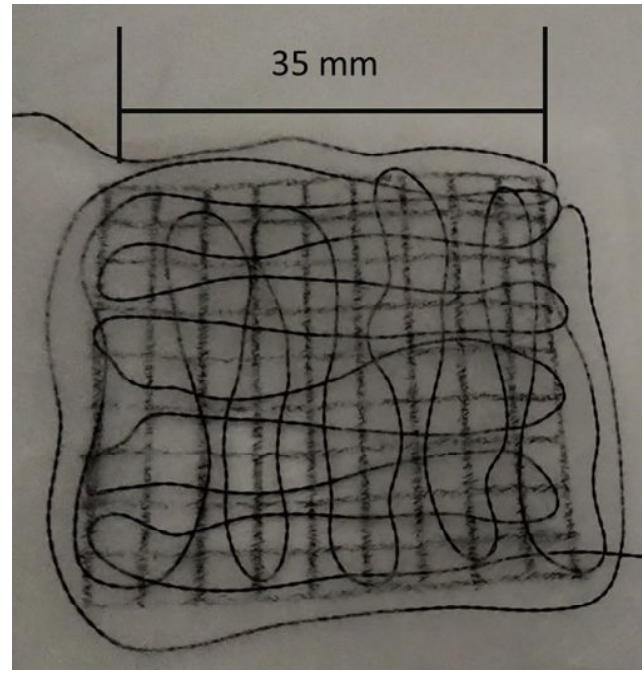

Figure 6. Twisted woven sensor made of Ny/PU twisted wire. 


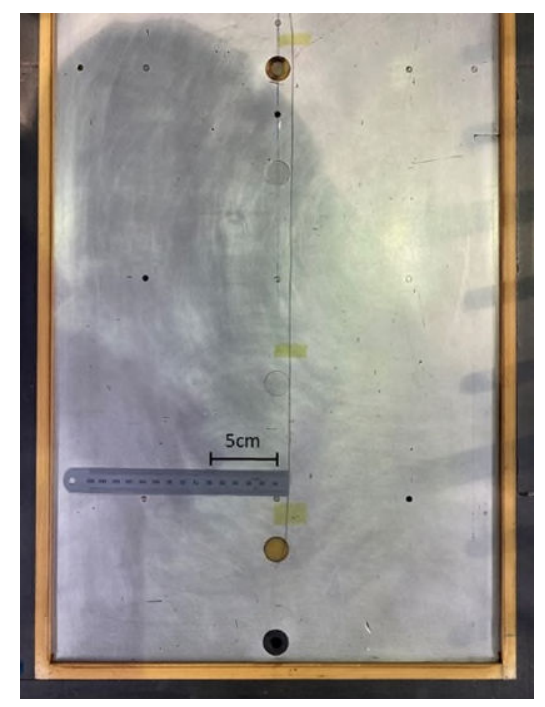

Figure 7. PI-LD flow sensor placed at the centre of the lower tool surface of the glass top RTM.

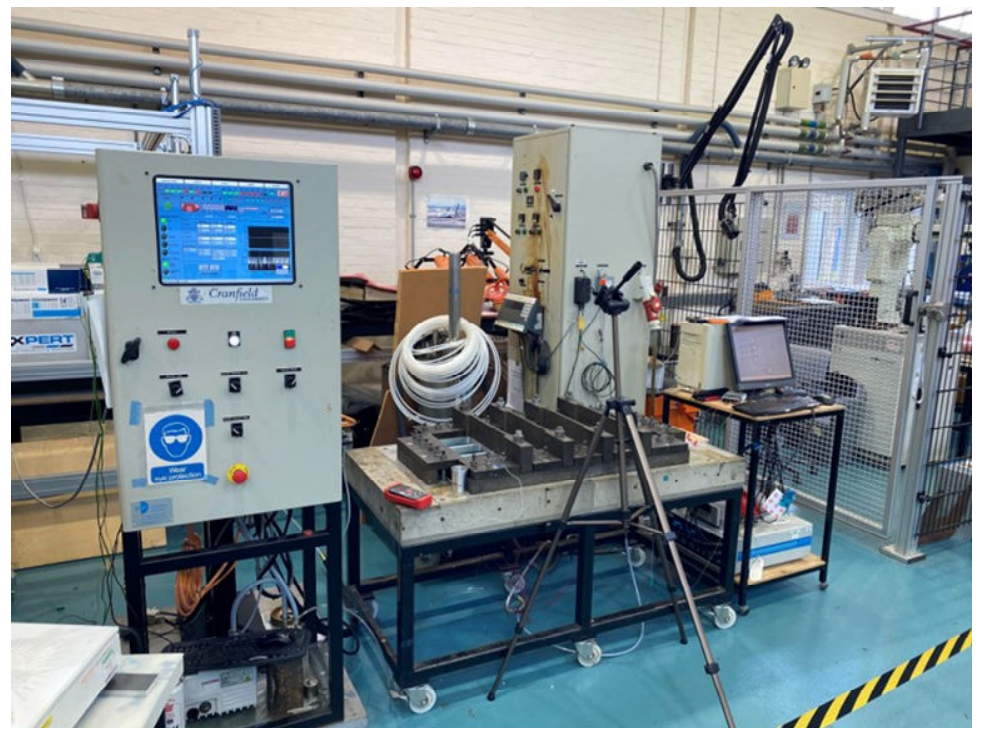

Figure 8. Experimental set-up used for glass top RTM trial. 
a)

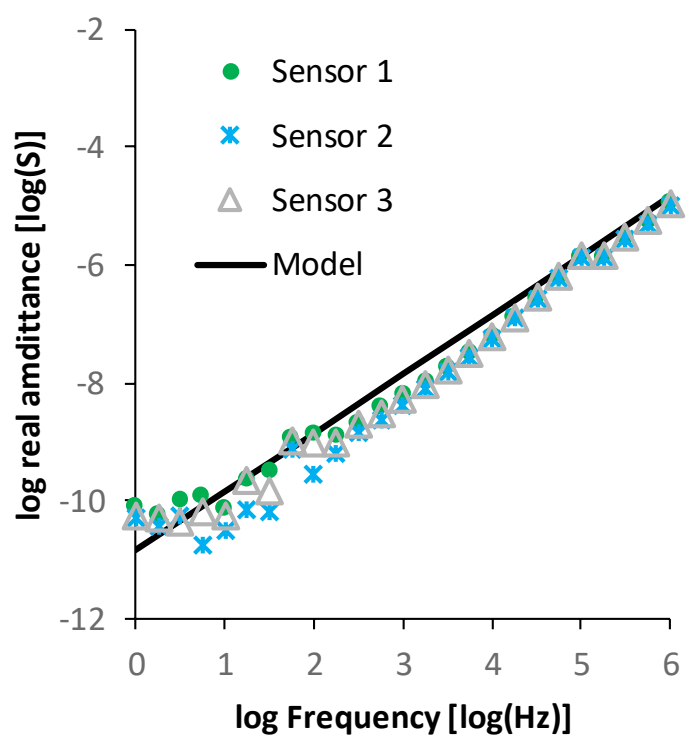

b)

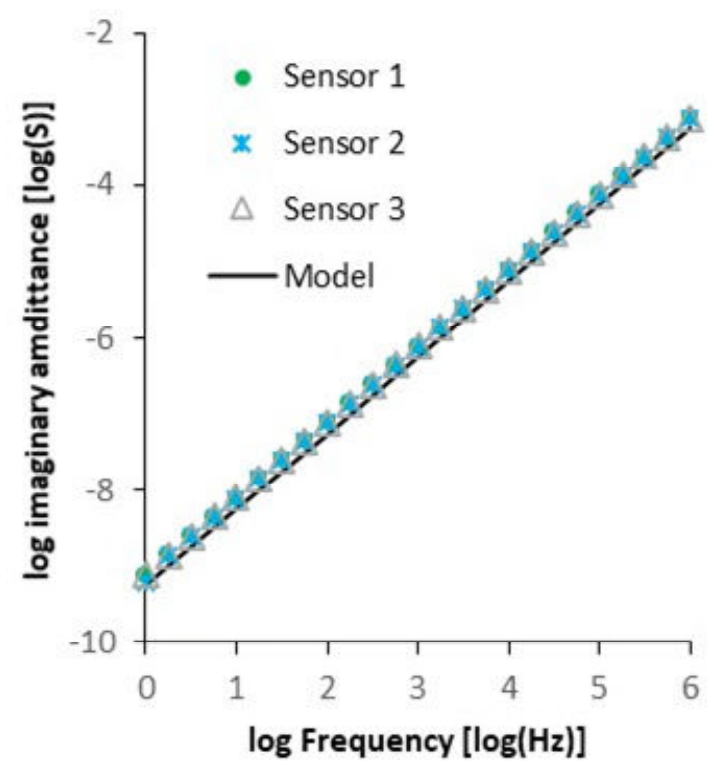

Figure 9. Real a) and b) imaginary admittance spectra of PU sensor in air.

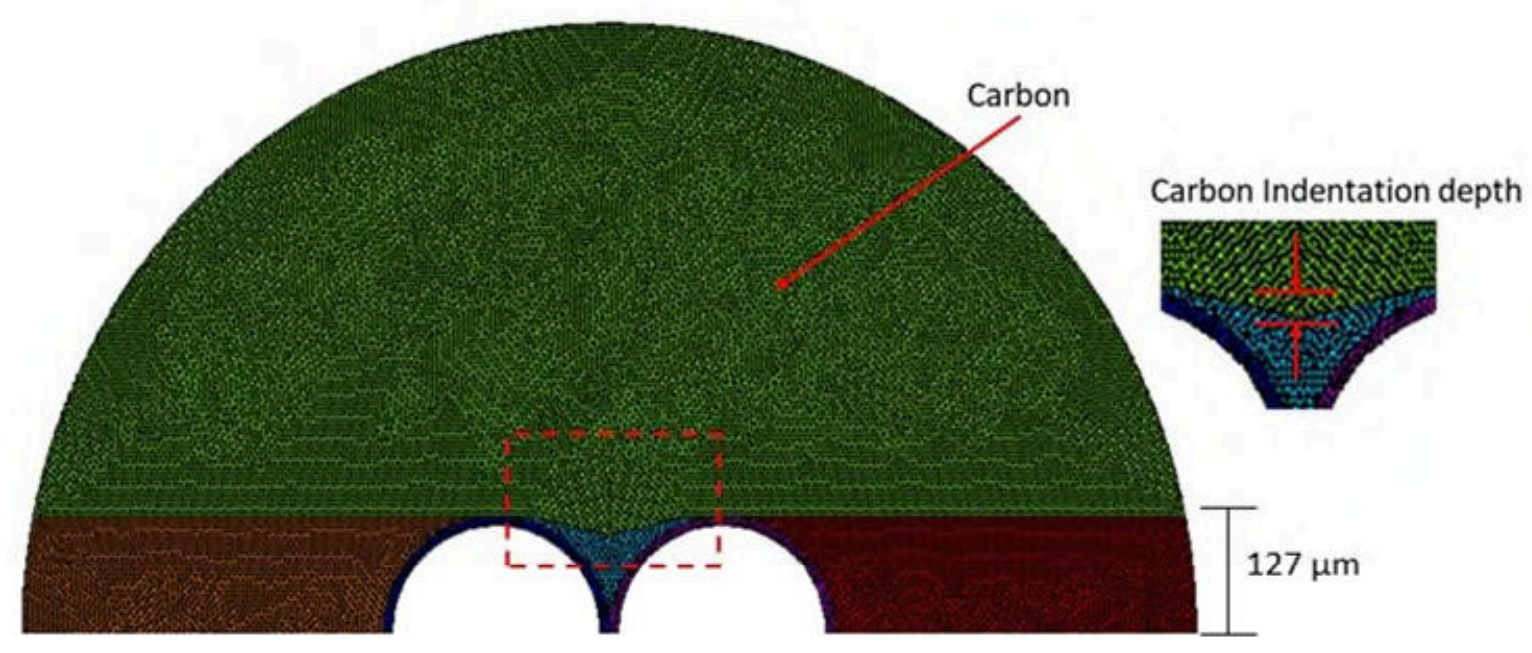

Figure 10. Sensor electric field model with carbon reinforcement indentation. 


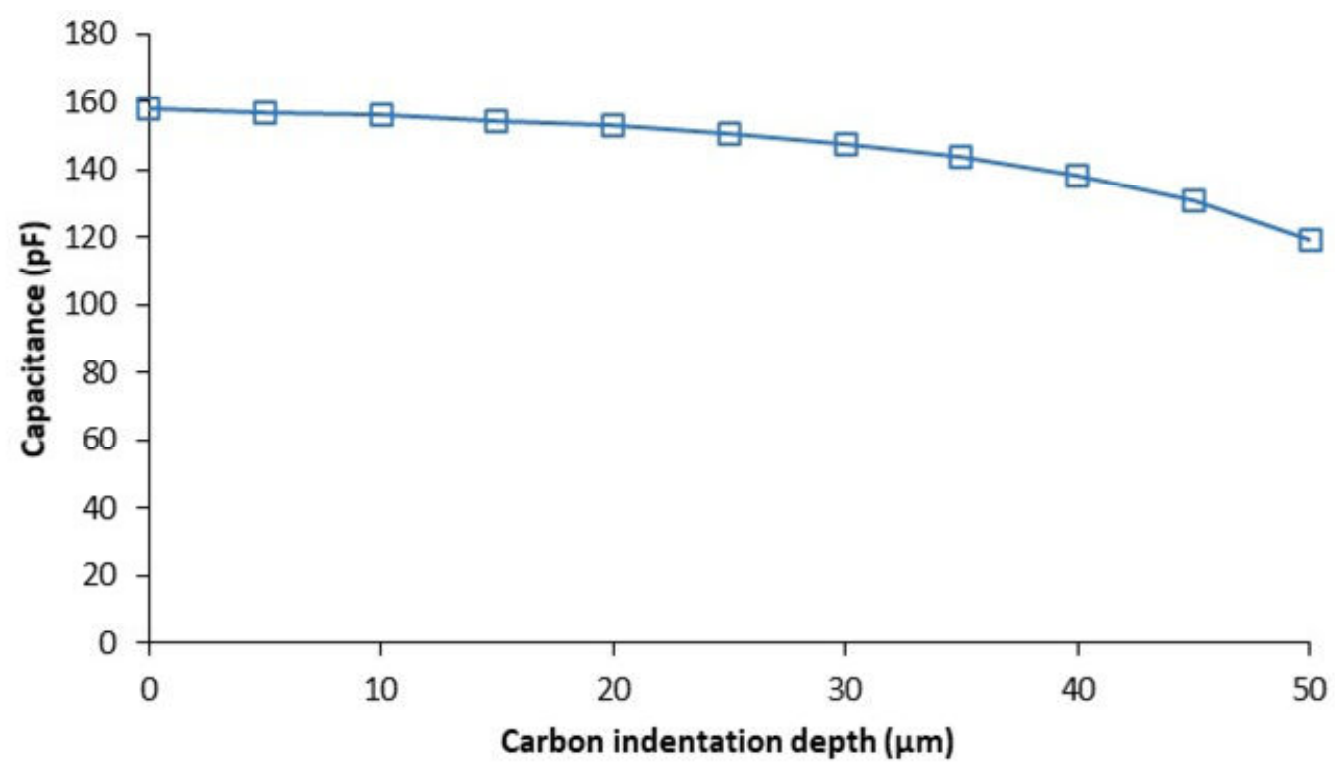

Figure 11. Effect of carbon indentation on sensor response.

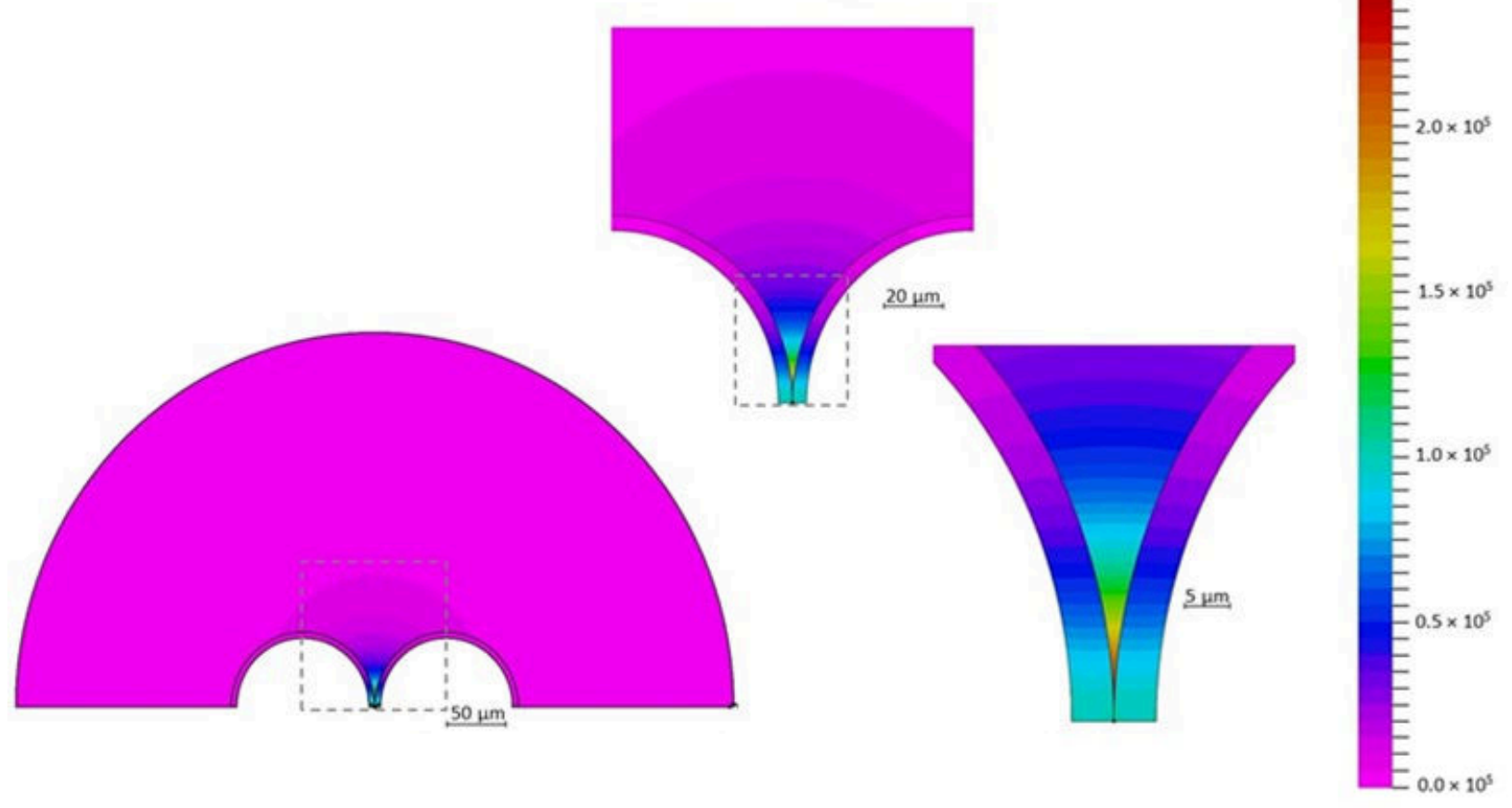

Figure 12. Real electric field distribution of sensor in air. Colour map units are V/m. 
a)

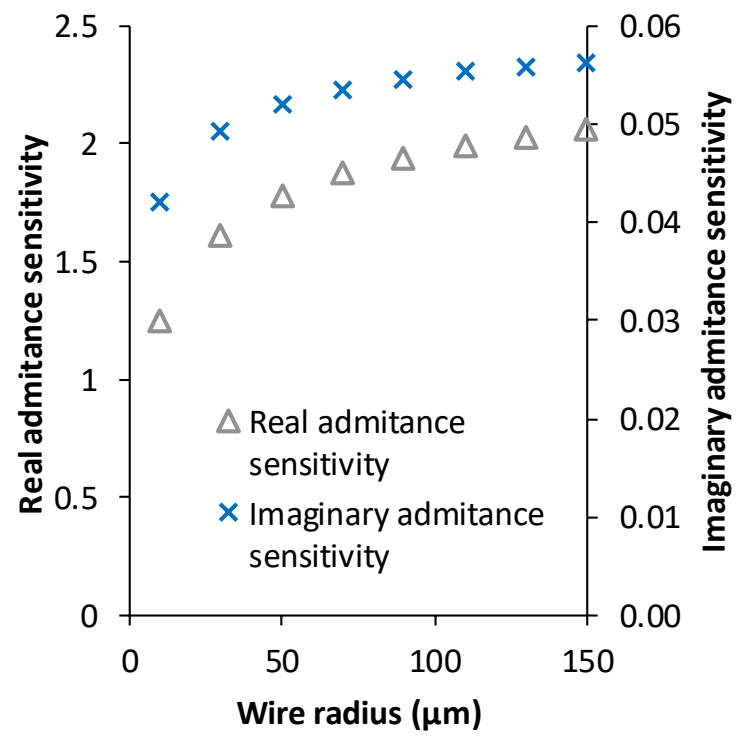

b)

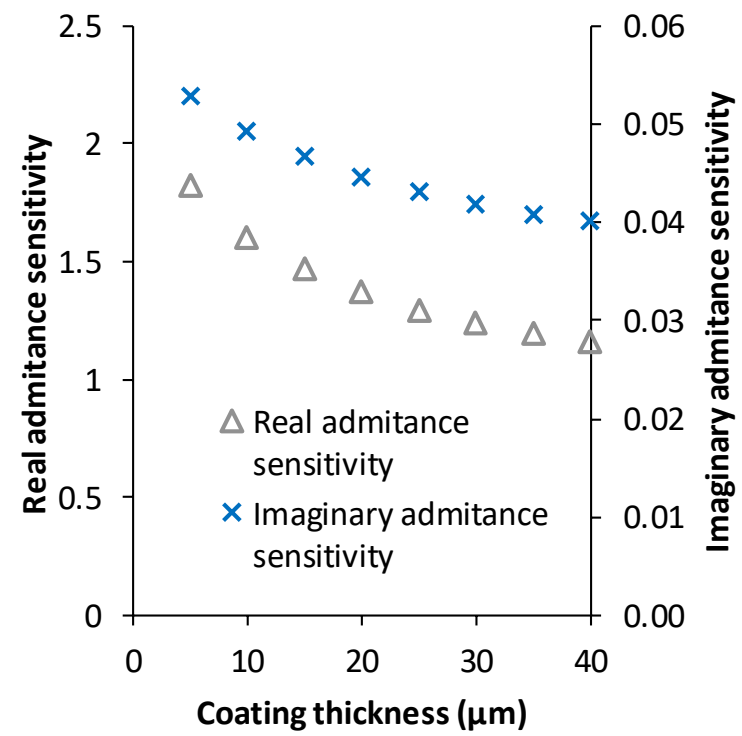

Figure 13. Sensitivity analysis: wire radius a), coating thickness b).

a)

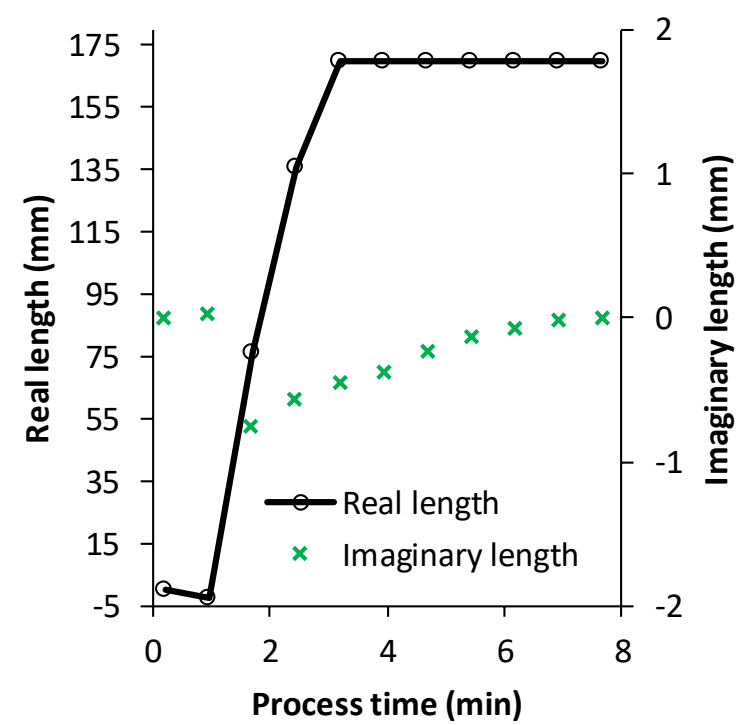

b)

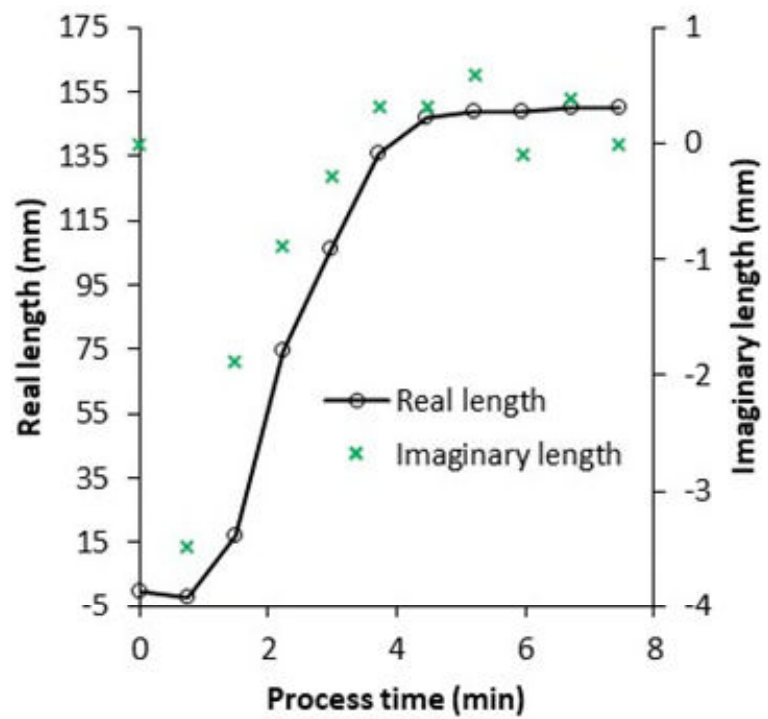

Figure 14. Dielectric flow measurement at $104.2 \mathrm{kHz}$ during RTM process with 7 bar clamping pressure, using a PI-LD lineal flow sensor a), and Ny/PU lineal flow sensor b). 
a)

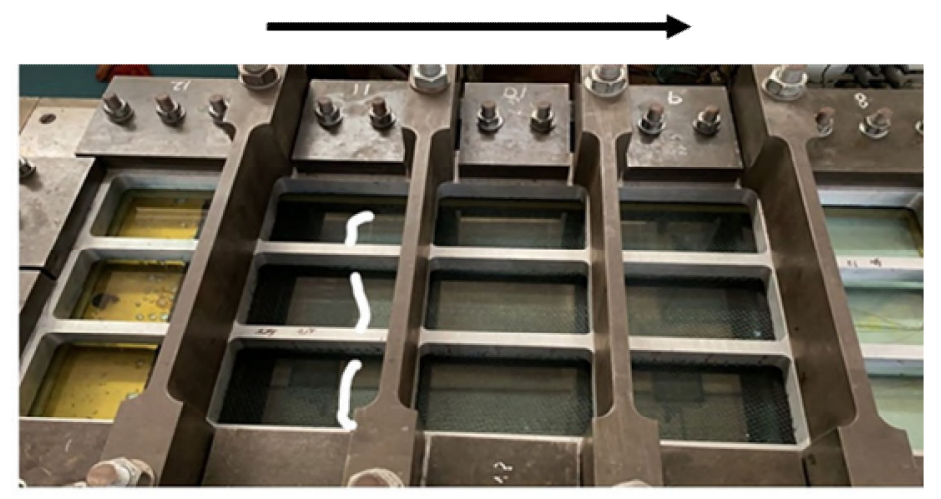

b)

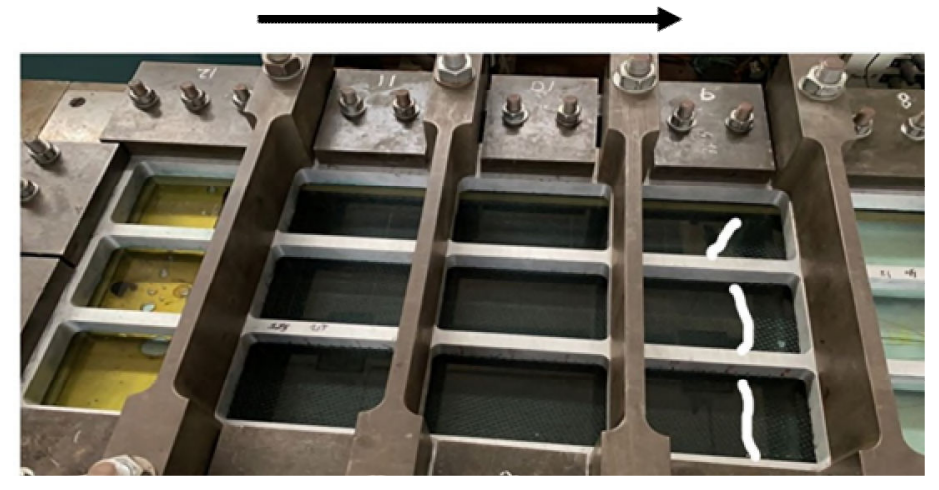

Figure 15. Visual flow front evolution during glass top RTM trial under 4 bar clamping pressure: 3.9 min a), $44.8 \mathrm{~min} b)$. 


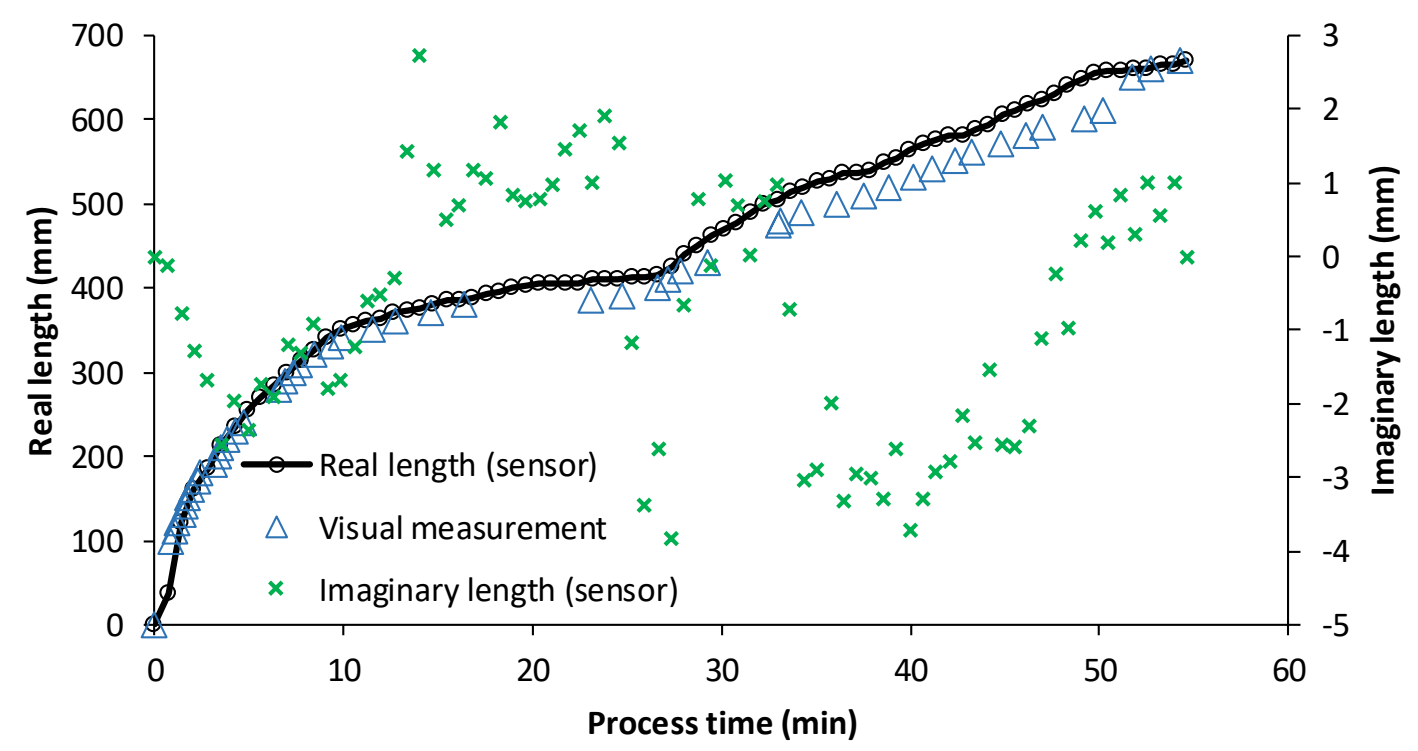

Figure 16. Comparison of visual with dielectric flow measurement at $1 \mathrm{MHz}$ using PI-LD- lineal flow sensor during glass top RTM trial under 4 bar clamping pressure.

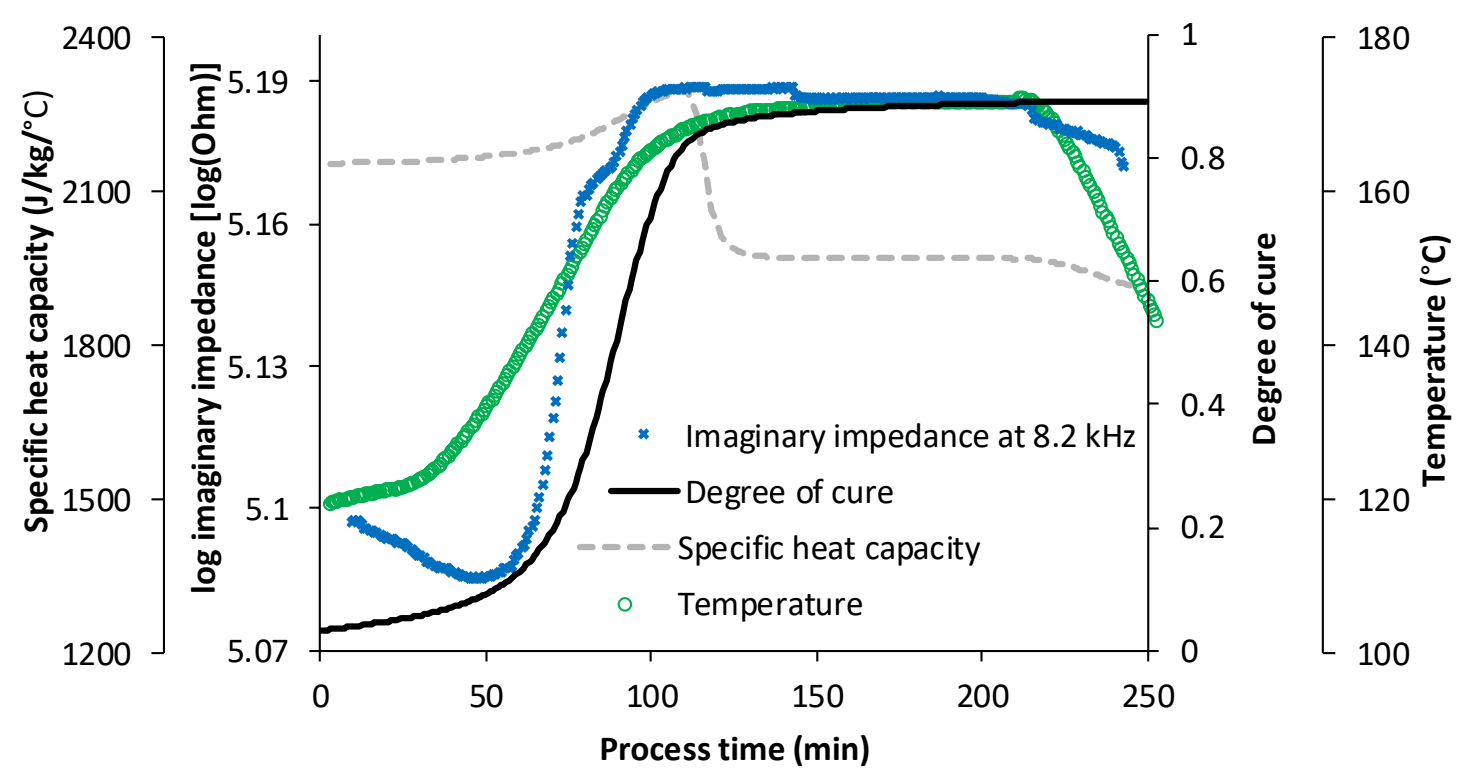

Figure 17. PI-LD woven cure sensor response during the curing stage of the RTM process at 7 bar clamping pressure: imaginary impedance evolution at $8.2 \mathrm{kHz}$ and comparison with degree of cure development and the evolution of specific heat capacity. 


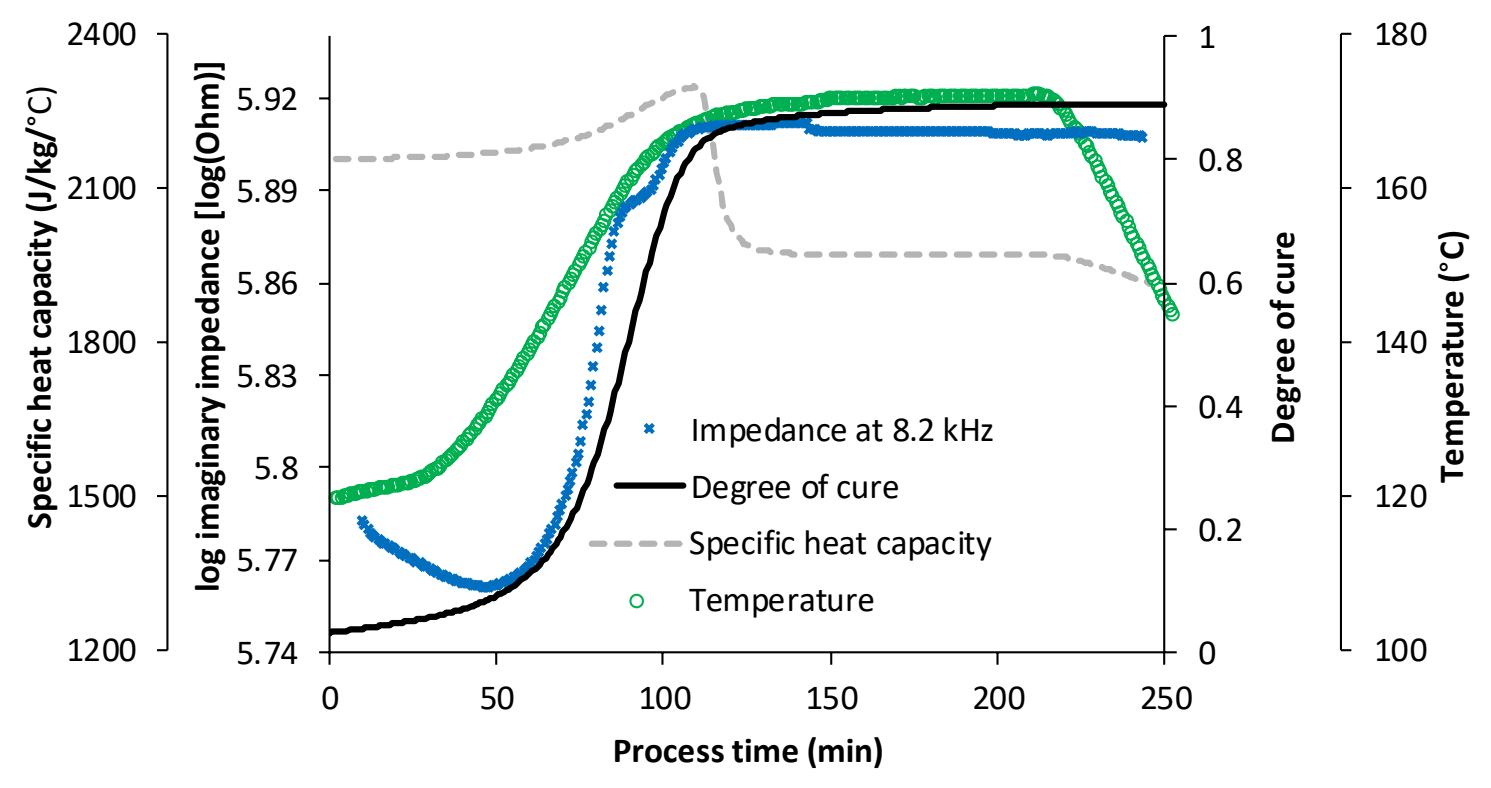

Figure 18. PI-LD lineal flow sensor response during the curing stage of the RTM process at 7 bar clamping pressure: imaginary impedance evolution at $8.2 \mathrm{kHz}$ and comparison with degree of cure development and the evolution of specific heat capacity.

a)

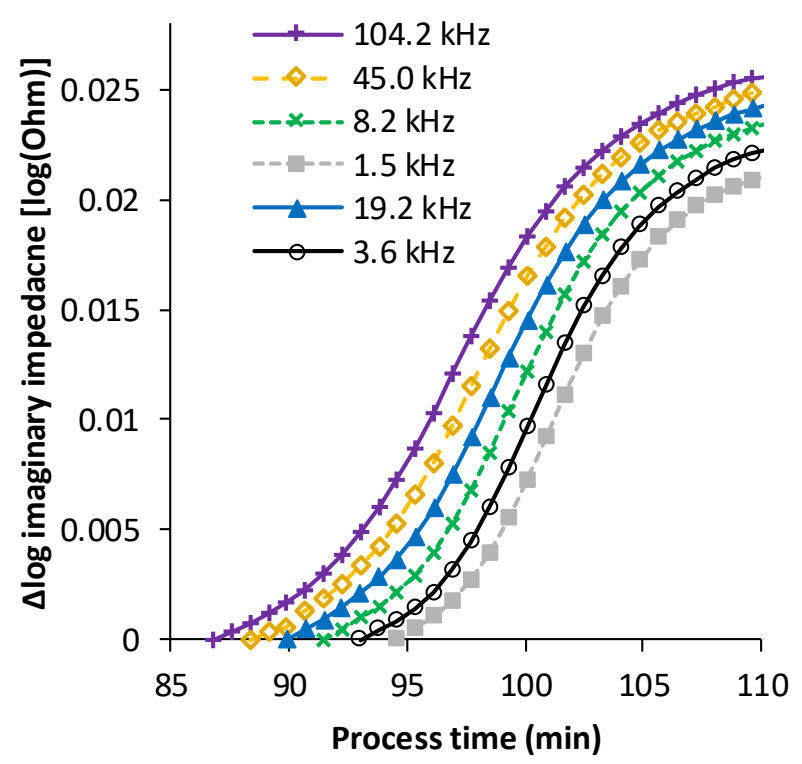

b)

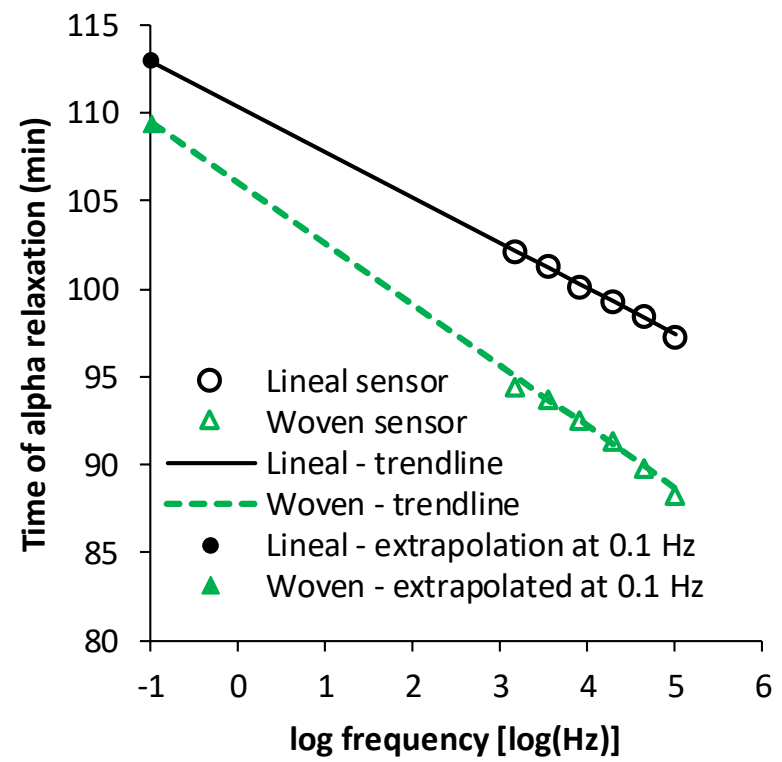

Figure 19. Identification vitrification by the PI-LD sensors: a) Shifted imaginary impedance spectra in the vitrification time interval; b) dependence of time of inflection point on the frequency of the impedance measurement. 
2020-11-04

\section{Optimisation of an in-process lineal dielectric sensor for liquid moulding of carbon fibre composites}

Mesogitis, T. S.

Elsevier

Mesogitis T, Maistros GM, Asareh M, et al., (2020) Optimisation of an in-process lineal dielectric sensor for liquid moulding of carbon fibre composites. Composites Part A: Applied Science and Manufacturing, Volume 140, January 2021, Article number 106190

https://doi.org/10.1016/j.compositesa.2020.106190

Downloaded from Cranfield Library Services E-Repository 